\title{
Joint attention at preschool age
}

\author{
Yana Smirnova ${ }^{1, *}$ \\ ${ }^{1}$ Altai State University, 656049, 61a Lenina ave., Barnaul, Russia.
}

\begin{abstract}
The article deals with the functions of joint attention with regard to ontogenetic development of arbitrariness and social coordination of group activity of preschool children. It is shown that the concepts of joint attention cover much more than just "visual joint attention" and require to consider of other forms of manifestations of mutual participation in joint activities. The manifestation of joint attention on the part of children themselves without the participation of adults is studied in the article. Response and initiation of joint attention are considered not only in the adult-child dyads, but also in a larger group of preschool children. The study involved 157 preschool children, who were organized during the experiment in subgroups to jointly solve problem situations. It is proved that in the structure of the regulation of joint activity different forms of manifestation of joint attention provide an afferent synthesis of the conditions of activity, facilitates the analysis of internal and external conditions of joint activity, the development of a program of conscientious activity.
\end{abstract}

\section{Introduction}

Joint attention is a social-cognitive phenomenon [8], which reflects the facts in the process of social cognition, and the joint processing of information about one's own attention and attention of other participants in joint activities takes place. Joint attention is the ability of a person to pay attention to the same object or event that another person pays attention to, which is of paramount importance for communication processes [10].

Joint attention is seen as the most important mechanism for coordinating joint actions and as an ability to attract the joint attention of another person [8].

Joint attention serves as a self-organizing role in the processing of social information in early, unstructured situations of social learning [1]. Such an orientation of attention can give an observer an indication of a person's mental state, as well as his/her attention and goals $[2,7,5]$. Manifestations of joint attention are social in the sense that a person using this mechanism begins to be guided by the fact that someone else is present and available for social interaction. Joint attention provides coordinated behavior models depending on the common intent of the participants in the joint action $[4,9]$.

\footnotetext{
* Corresponding author: yana.smirnova@ mail.ru
} 
Joint attention can be made in any form of perception, and is confirmed in a speech message in some cases [5]. Language can take on the functional role of deliberately initiating joint attention, enabling successful collaboration in collaborative activities [8,9].

However, there remains a little studied area in (a) how a child uses speech to initiate joint attention of peers the future ontogeny and (b) how joint attention is organized not only in dyadic (one on one), but also in polyadic (group) interactions, since joint actions can occur not only in triadic relations (person-second participant-object) but also in situations of group interactions.

Thus, the purpose of the study was to characterize the joint attention given the real polyadic context in which preschoolers interact with others.

\section{Materials and methods}

An empirical sample. 157 young children aged 5-7 years $(\mathrm{M}=6.5, \mathrm{SD}=0.38)$ participated in the study. The study was conducted in organized microgroups of 5-7 people.

Methods of empirical research:

1. Standardized psychodiagnostic techniques for fixing the data: the technique of problem situations "put on a doll," "mosaic"; "let's do it together" (I. B. Dermanova); the technique aimed at investigating susceptibility to peer influence (T. P. Avdulova, O. V. Kuznetsova); the method of encoding (modification of the Pieron-Rouzer method).

2. During the research, experimental conditions were created for solving problem situations in which children were faced with the need to solve a social problem (to share or not to share with a peer, to evaluate his/her actions, to resolve a conflict, etc.). These situations provoked a process of joint attention. In all the above-mentioned problem situations, children's behavior indicators were noted.

3. The methods of mathematical-statistical processing is the regression analysis. The processing was carried out using the statistical package SPSS 23.0.

\section{Results}

With the help of regression analysis, parameters were identified that reflect different ways of responding to the attraction of joint attention and initiating joint attention that affect the process of joint activity in the preschool children.

Variables that affect the response to attracting joint attention.

The control function of the indicative basis of joint activities will be manifested in the fact that monitoring the actions of the partner reduces the inertia, as well as stiffness in actions of the preschool children $(\mathrm{R} 2=0.334, \mathrm{p}=0.05)$. At the same time, it was noted that those children who took notice of the progress made by a peer in a similar task while performing an individual task (for example, they compared how another child was performing the task) often began to regulate the behavior of partners when already performing a series of group joint assignments $(\mathrm{R} 2=0.794, \mathrm{p}=0.042, \beta=0.328)$.

The direct dependence of the frequency of helping partners on the positive nature of participation in peer actions is confirmed (the child approves, gives advice, and helps his/her peers) $(\mathrm{R} 2=0.670, \mathrm{p}=0.002, \beta=0.767)$. Preschoolers will have such reactions to attract attention as an interested glance towards a peer, periodic and close monitoring of the actions of their peers, individual questions or comments to peer activities, close monitoring and active intervention in peer activities.

Some predictors initiating joint attention by preschool children were singled out separately. Children with lower indices of inertia often give replies and advice about the work of partners $(\mathrm{R} 2=0.671, \mathrm{p}=0.024, \beta=-0.671)$, that is, they often initiate the 
association with other partners in the activity. When organizing a game, those preschool children who distribute joint toys more often among all participants (they also can take toys altogether) begin to regulate their partner's behavior more often (R2 $=0.794, p=0.001, \beta=$ 0.632). Understanding and acceptance by preschoolers of instruction is a predictor of an inverted speech to a partner, the presence of verbal accompaniment and replicas about actions for a partner, as well as the presence of an inverted speech to an adult ( $R 2=0,672$, $\mathrm{p}=0,0001$ ).

The frequency of assisting a partner will depend directly on the use of speech addressed to such a partner by preschoolers $(\mathrm{R} 2=0.683, \beta=0.742, \mathrm{p}=0.005)$. One can talk about the functional use of speech in the coordination of actions, the inclusion of a partner in their own actions, and the pooling of attention.

The number of mistakes in joint activities of preschool children $(\mathrm{R} 2=0.949, \mathrm{p}=$ 0.0001 ) increases if they do not use personal plural pronouns in the speech ("we" and "us") during the organization and performance of joint activities $\beta=-0.131$ ), as well as when they do not give a replica about the work of partners $(\beta=-0.230)$. In turn, the number of errors in solving a joint problem is reduced if the speech of preschool children is more often addressed to a partner $(\beta=0.151)$.

Speech control of preschool children due to initiating the attention of peers ensures the selective nature of activity and forms the ability to inhibit immediate reactions to the situation, the violation of which leads to the appearance of impulsiveness in behavior. Other components associated with the action of speech afferentation allow a child to create preliminary syntheses, directing the further course of activity, monitor the performance of actions, and adequately assess their results.

\section{Discussion}

One can single out such features of the manifestation of joint attention in group activities of the preschool children: initiative, sensitivity to peer influences, and prevailing emotional background.

A special role is played by the manifestation of joint attention through speech: speech forms of orientation, initiation of joint attention in speech form, response to the attraction of joint attention in speech form, and initiation of behavioral reactions in speech form.

Thus, joint attention will promote rational cooperation by creating a special form of social interaction through which preschoolers coordinate their actions in space and time.

\section{Conclusion}

Joint attention is needed to maintain coordinated behavior patterns along the way to achieve the goal. Joint attention plays a functional role in the tentative-research part of joint activities and promotes an effective study of the conditions for the implementation of joint activities. By means of joint attention, the composition of the signs is highlighted, which should be guided in the course of joint activities.

Participation in joint models of behavior (determined in varying degrees by rules or patterns) to achieve the goal helps preschoolers to form control behavior through the mechanism of joint attention. By means of joint attention, preschoolers receive information about general awareness of the conditions of activity and use the mechanism of joint attention in organizing joint search.

\section{Acknowledgements}


The article is published within the framework of the Grant of the President MK3052.2018.6 "Formation of mechanisms of arbitrary regulation of the indicative part of joint activity in the early stages of ontogenesis" (Grant prezidenta MK-3052.2018.6 «Stanovleniye mekhanizmov proizvolnoy regulyatsii oriyentirovochnoy chasti sovmestnoy deyatelnosti na rannikh etapakh ontogeneza».).

\section{References}

1. D. A. Baldwin, (1995). Joint attention: its origin and role in development (Routledge, London, 1995)

2. S. Baron-Cohen, Mind blindness (MIT Press, Cambridge, 1997)

3. P. J. Brooks, V. Kempe, Language development (Chichester, 2012).

4. M. Carpenter, K. Liebal, Joint attention: new developments in Psychology, Philosphy of Mind, and Social Neuroscience. (MIT Press, Cambridge, 2011)

5. A. Frischen, A. P. Bayliss, S. P. Tipper, Psychol Bull, 133, 4 (2007)

6. E. F. Risko, K. E. W. Laidlaw, M. Freeth, T. Foulsham, A. Kingstone, Front Hum Neurosci, 6, 143 (2012)

7. S. P. Tipper, S. Grison, K. Kessler, Psychol Sci, 14, 1 (2003)

8. M. Tomasello, Why we cooperate (MIT Press, Cambridge, 2009)

9. M. Tomasello, M. Carpenter, J. Call, T. Behne, H. Moll, Behavioral and Brain Sciences, 28, 5 (2005)

10. T. V. Akhutina, K. V. Zasypkina, A. A. Romanova, Voprosy Psicjolingvistiki, 7, 4 (2013) 